\title{
SUSTENTABILIDADE NO SETOR SUPERMERCADISTA: ESTUDO COMPARATIVO DE GRANDES REDES NO BRASIL E NO EXTERIOR
}

\author{
A. L. C. F. GALLARDO ${ }^{* * *}$, A. J. C. WINANDY ${ }^{* * *}$, J. P. L. SIQUEIRA , F. HOURNEAUX Jr ${ }^{* *}$ \\ Universidade Nove de Julho - Uninove ${ }^{*}$, Universidade de São Paulo - USP**, Associação Brasileira de \\ Supermercados - ABRAS ${ }^{* *}$ \\ amarilislcfgallardo@gmail.com*,**
}

Submetido 08/12/2013 - Aceito 19/09/2017

DOI: $10.15628 /$ holos.2017.1865

\section{RESUMO}

O setor de supermercados é expressivo em termos econômicos, ambientais e sociais. No entanto, sua contribuição para a promoção da sustentabilidade segue como um desafio para esse segmento. O objetivo deste artigo é analisar o alinhamento entre a política ambiental de grandes redes do setor supermercadista às prioridades internacionais para a sustentabilidade. Para isso, realizou-se uma pesquisa exploratória, na qual foi selecionada uma amostra de supermercados do Brasil e do exterior (Itália, Inglaterra e Estados Unidos) que apresentam políticas e práticas voltadas à sustentabilidade como critério de seleção. A partir de uma análise comparativa, observou-se que, apesar da existência de iniciativas por parte das empresas domésticas, principalmente no que se refere à gestão de resíduos, os supermercados estrangeiros apresentam melhores práticas em termos de sustentabilidade do que aqueles que atuam no Brasil. Os supermercados estrangeiros também tem uma posição mais consolidada ao considerarem a sustentabilidade como critério para a criação de políticas ambientais. Dessa forma, a principal contribuição desse estudo é demonstrar as diferentes situações entre as empresas e os critérios utilizados pelos supermercados no que se refere à promoção da sustentabilidade na agenda ambiental do seu negócio.

PALAVRAS-CHAVE: sustentabilidade, política ambiental, varejo supermercadista, impacto ambiental.

\section{SUSTAINABILITY IN THE SUPERMARKET SECTOR: COMPARATIVE STUDY OF LARGE RETAIL SUPERMARKET NETWORKS IN BRAZIL AND OTHER COUNTRIES}

\begin{abstract}
The supermarket industry is expressive in economic, environmental and social aspects. However, to contribute to the promotion of sustainability remains as a challenge for this segment. This article aims to analyze the alignment between the environmental policy of large networks in the supermarket sector and the international priorities for sustainability. To accomplish this goal, an exploratory research was carried out, with a sample of supermarkets from Brazil and abroad (Italy, England and the United States) that present policies and practices related to sustainability as criteria for selection. Based on a comparative analysis, it is
\end{abstract}

possible to observe that, despite the existence of initiatives by domestic companies, especially about waste management, foreign supermarkets present better practices regarding sustainability than those operating in Brazil. Foreign supermarkets also have a more consolidated position in considering sustainability as a criterion for the creation of environmental policies. Thus, the main contribution of this study is to demonstrate the different situations among the companies and the criteria used by the supermarkets regarding the promotion of sustainability in the environmental agenda of their business. 


\section{Introdução}

Desde as primeiras discussões sobre sustentabilidade, as consequências de uma mudança de forma de pensar nas organizações são inegáveis e têm sido abordadas por meio de diferentes prismas na literatura especializada: seus aspectos mais estratégicos (p. ex. Hunt \& Auster, 1990; Hart, 1997; Aragón-Correa, 1998); o papel da inovação na sustentabilidade (Porter \& Van Der Linde, 1995); as chamadas estratégias de marketing verde (Wells, 2006); a reocupação com o rigor da legislação ambiental (Demajorovic, 2006); até o aumento da produtividade e da criatividade no ambiente profissional (Barbieri, 2007). A definição mais conhecida de sustentabilidade cita a busca do uso de recursos no curto prazo sem que haja comprometimento dos recursos necessários no longo prazo, preservando as condições para as futuras gerações (World Comission on Environment and Development, 1987).

Dessa forma, a evolução das práticas socioambientais caminha para um alinhamento estratégico consistente com a empresa e sua missão, ajudando a construir no longo prazo a sustentabilidade empresarial, com o negócio da empresa apoiado em um tripé composto de aspectos não só econômicos, mas também ambientais e sociais (Amadeu Junior, Gelman, \& Macedo, 2008).

Dentre as várias atividades econômicas existentes, o supermercado é considerado o principal canal de distribuição de alimentos em nosso país (Superhiper, 2010). De acordo com a classificação do Instituto Brasileiro de Geografia e Estatística (2012), representa mais de 40\% do comércio nacional e uma participação de 5,4\% no PIB brasileiro (Superhiper, 2012). O setor de supermercados responde por $85 \%$ do volume de vendas de produtos de largo consumo no país (Associação Paulista de Supermercados, 2008a). Dada essa expressão do setor, os supermercados ocasionam por uma série de impactos ambientais e sociais significativos (Suamir, Tassou, \& Marriot, 2012).

Internacionalmente, a introdução da preocupação com a sustentabilidade na área dos supermercados é algo relativamente recente, podendo ser citados como exemplos disso o guia para inserção de sustentabilidade nos negócios dos supermercados da Nova Zelândia (Christchurch City Council, 2008) e o guia para implementação de sustentabilidade nas operações do varejo nos Estados Unidos (Food Market Institute, 2013). No Brasil, há pouco tempo, surgiram as primeiras iniciativas para internalização da variável ambiental no setor varejista, como o guia da loja verde para supermercados (Associação Paulista de Supermercados, 2011) e o banco de práticas do sítio varejo sustentável (Varejo Sustentavel, 2012), voltado ao varejo em geral.

Este estudo, de natureza exploratória, tem o objetivo de analisar o alinhamento entre a política ambiental de grandes redes do setor supermercadista às prioridades internacionais para a sustentabilidade. A amostra é composta por empresas supermercadistas, tanto do Brasil como do exterior (países da Europa e Estados Unidos), que apresentam políticas e práticas voltadas aos aspectos socioambientais relevantes para sua atuação. Foi feita uma identificação e uma análise comparativa das políticas e práticas à luz das principais diretrizes internacionais para a sustentabilidade, optando-se por utilizar o referencial estabelecido por Seiffert (2007). Estabelecem-se três questões de pesquisa: 1) Como as práticas voltadas à sustentabilidade 
encontradas nas grandes redes de supermercado do Brasil e do Mundo se alinham às prioridades internacionais da sustentabilidade? 2) Qual o estágio das redes supermercadistas internacionais e as nacionais nesse contexto?

\section{REFERENCIAL BIBLIOGRÁFICO}

O referencial teórico aborda os temas sustentabilidade, responsabilidade social empresarial e gestão ambiental no varejo supermercadista.

\subsection{Sustentabilidade e a Responsabilidade Social Empresarial}

A Responsabilidade Social Empresarial (RSE) aparece nos EUA e Europa na década de 1950. RSE é a forma de gestão que se define pela relação ética e transparente da empresa com todos os públicos com os quais ela se relaciona e pelo estabelecimento de metas empresariais que impulsionem o desenvolvimento sustentável da sociedade, preservando recursos ambientais e culturais para as gerações futuras, respeitando a diversidade e promovendo a redução das desigualdades sociais (Instituto Ethos, 2010; Borger, 2006).

De uma forma mais abrangente, Porter e Kramer (2009) destacam quatro razões para a adoção de RSE: reputação, licença para operar, obrigação moral e sustentabilidade; argumentam que se inicialmente não foi um movimento voluntário, a reação não deveria apenas ser cosmética com ações alardeadas em vistosos relatórios, desconexas com o negócio da empresa e sua estratégia, mas que a adoção da RSE poderia ser fonte de oportunidade, inovação, vantagem competitiva.

A norma da Associação Brasileira de Normas Técnicas (2012) a NBR 16001, que trata de Responsabilidade Social, é uma norma de gestão ambiental, em que está definida a responsabilidade de uma organização pelos impactos de suas decisões e atividades (produtos, serviços e processos) na sociedade e no meio ambiente, por meio de um comportamento ético que: contribua para o desenvolvimento sustentável, inclusive a saúde e o bem estar da sociedade; considere as expectativas das partes interessadas; que esteja em conformidade com a legislação aplicável e seja consistente com as normas internacionais de comportamento; e que esteja integrada em toda a organização e seja praticada em suas relações.

A partir de ampla revisão bibliográfica, Seiffert (2007) realizou um levantamento sobre prioridades de intervenção para o alcance do desenvolvimento sustentável, constituindo o que a autora definiu como "Prioridades internacionais para a sustentabilidade", divididas em doze categorias: reduzir o crescimento populacional; diminuir a pobreza, as desigualdades e a dívida do Terceiro Mundo; praticar a agricultura sustentável; proteger florestas e habitats, limitar a perda de espécies; proteger os recursos oceânicos e costeiros; proteger a qualidade da água doce, melhorar a eficiência do uso da água; aumentar a eficiência energética; desenvolver fontes renováveis de energia; limitar os gases de estufa e outros poluentes atmosféricos; proteger a camada de ozônio; reduzir a geração de lixo, reciclar os rejeitos (resíduos e efluentes); transferir os gastos militares ao desenvolvimento sustentável (Seiffert, 2007, p. 40). Esta categorização servirá como proxy para os propósitos deste estudo. 
Tal diretriz fundamenta-se também pela pesquisa realizada por Hamza e Dalmarco (2013). Esses autores desenvolveram pesquisa empírica com 5 grandes redes de supermercados brasileiros e verificaram que para apenas 3, as práticas de RSC estão mais desenvolvidas, havendo ainda espaço para um melhor alinhamento entre as práticas de sustentabilidade e RSC.

\subsection{Sistemas de Gestão Ambiental}

A gestão ambiental é um processo que se inicia quando são promovidas adaptações ou modificações no ambiente natural para adequação às necessidades individuais ou coletivas. Este processo de gestão deve estar fundamentado em três variáveis, a diversidade de recursos extraídos deste ambiente natural, sua velocidade de extração relacionada com a sua possibilidade de reposição e, a maneira de dispor e tratar seus resíduos e efluentes (Philippi Junior; Roméro; Bruna, 2009).

Para Epelbaum (2006, p. 116), “[...] a gestão ambiental pode ser entendida como a aplicação dos princípios de planejamento e controle na identificação, avaliação, controle, monitoramento e redução dos impactos ambientais a níveis pré-definidos". "Sistema de gestão ambiental é um conjunto de atividades administrativas e operacionais inter-relacionadas para abordar os problemas ambientais atuais ou para evitar seu surgimento" (Barbieri, 2004, p. 137). Definição semelhante é a da ABNT NBR 14001:2004 que considera o SGA como parte de um sistema de gestão da organização, para gerenciar seus aspectos ambientais (atividades, produtos, ou serviços e sua interação com o meio ambiente, que podem causar impactos ambientais, que são modificação, benéficas ou ao contrário, no meio ambiente), desenvolvendo e implantando uma política ambiental (intenções expressas pela organização).

A gestão ambiental compreende atividades administrativas e operacionais, como de planejamento, direção e controle, objetivando a eliminação ou redução de danos e problemas causados pelo homem, ou evitando seu surgimento, e envolvendo sempre três dimensões: a espacial, que define a abrangência de atuação das ações de gestão, a institucional, que define o alcance institucional e os agentes responsáveis, e a temática, que por sua vez define as questões ambientais que estão envolvidas (Barros, 2005).

A adoção de um Sistema de Gestão Ambiental (SGA) permite organizar ações em prol do controle e enfrentamento das suas consequências indesejáveis sobre o meio ambiente. Moura (2011) orienta que, para a implantação de um sistema de gestão ambiental devem ser cumpridos três grandes conjuntos de atividades: análise da situação atual da empresa (onde estamos), estabelecimento de metas (onde queremos chegar) e, métodos (como chegar). Um dos componentes da dimensão institucional é a empresa, cuja gestão ambiental é denominada por Barbieri (2004) de gestão ambiental empresarial.

Para Barros (2005), a criação de um SGA necessita da formulação de diretrizes, da definição de objetivos, da coordenação de atividades e da avaliação de resultados, além de implantação da política ambiental.

De Araujo e Carvalho (2011) destacam a relevância da adoção de ações de responsabilidade social no que tange a sistemas de gestão ambiental pelas redes varejistas. 
Segundo esses autores a gestão ambiental no segmento permite influenciar o comportamento do consumidor, representar vantagem competitiva e valor para a marca, além de contribuir para valorizar as variáveis ambientais e sociais associadas ao setor. Winandy e Gallardo (2014) analisaram as práticas de gestão ambiental divulgadas por redes de supermercados nacionais e internacionais e demonstraram que há alinhamento entre as práticas ambientais adotadas pelo setor e o alcance dos sistemas de gestão ambiental estabelecidos.

\subsection{Sustentabilidade no setor varejista e nos supermercados}

A parte do meio ambiente nos indicadores de responsabilidade social nas empresas varejista é dividida em dois grandes grupos, responsabilidade frente às gerações futuras e gerenciamento do impacto ambiental (Fundação Getúlio Vargas, 2005). O primeiro com dois indicadores, comprometimento da empresa com a melhoria da qualidade ambiental e educação e conscientização ambiental; o segundo com três indicadores, gerenciamento do impacto no meio ambiente e do ciclo de vida de produtos e serviços, sustentabilidade da economia florestal e, minimização de entradas e saídas de insumos.

A Associação Paulista de Supermercados (2011) lançou o guia da loja verde, com orientações quanto à infraestrutura de loja, saúde, gestão, operações das seções, comunicação e engajamento, além de questionário de avaliação da sustentabilidade do supermercado; na parte de gestão, orientação para consumo de água e energia, geração de resíduos e uso de sacolas.

Outras iniciativas significativas, neste caso para varejo, são feitas pela FGV/EAESP e CEV (Fundação Getúlio Vargas/Escola de Administração de Empresas de São Paulo e seu núcleo de varejo, o Centro de Excelência em Varejo), como o sítio na Internet sobre Varejo Sustentável, a realização do Fórum de Varejo e Consumo Sustentável em 2009, e iniciativas como o trabalho "Indicadores de Responsabilidade Social nas Empresas Varejistas" (Fundação Getulio Vargas, 2005).

Um exemplo é o guia prático da Associação Paulista de Supermercados (2008b), com conteúdo desenvolvido pelo GVcev - Centro de excelência em varejo da FGV-EAESP, que por sua vez mantém um programa de responsabilidade social e sustentabilidade no varejo, e publicou, em 2009, o guia prático FGV - GVcev de responsabilidade social e sustentabilidade no varejo, ajudando empresas do setor a fazer um diagnóstico de práticas de RSE na empresa e, consequentemente de sustentabilidade na gestão.

O guia prático da FGV - GVcev (Associação Paulista de Supermercados, 2008b) concentrase em oito temas, dentre os quais, destacam-se os ambientais, como a adoção de critérios de sustentabilidade nas compras, a avaliação de impactos sociais e ambientais de sua operação, lojas sustentáveis, e contribuição para o desenvolvimento sustentável da sociedade e do planeta. 0 guia menciona ações que mediriam a sustentabilidade no varejo e, portanto, deveriam ser adotadas em uma política ambiental das empresas.

Em um estudo comparativo, Cruz, Pedrozo e Martinet (2007, p. 71) analisaram a estratégia voltada à sustentabilidade de duas grandes empresas varejistas internacionais com a de suas filiais no Brasil, quanto a ações de governança corporativa, ética empresarial e aprendizagem 
organizacional, "[...] mostrando o constante processo de deliberação/emergência presente na relação matriz e filial [...]", quanto ao desenvolvimento sustentável nesses três temas.

Apesar dessas iniciativas, a pesquisa recente e específica sobre o tema realizada por Delai e Takahashi (2013) revela que tanto a academia nacional como internacional não tem dado o devido destaque para a discussão do tema promoção de sustentabilidade no varejo. Wiese, Kellner, Lietke, Toporowsi e Zielke (2012) destacaram o atraso de mais de dez anos no emprego do termo sustentabilidade às operações de varejo em comparação, por exemplo, com a indústria. Spence e Bourlakis (2009) também destacaram a escassez de trabalhos que examinam empiricamente o tema RSE nas cadeias de varejo, assim como o de Erol, Cakar, Erel e Sari (2009), com relação especificamente ao tema sustentabilidade na indústria do varejo supermercadista.

De modo geral, as questões ambientais têm ganhado espaço no varejo, destacando-se a gestão de resíduos, produtos e embalagens; no entanto, os conceitos de responsabilidade socioambiental ainda se encontram em processo de desenvolvimento nesse setor (Braga Jr, 2007). De acordo com Walker (2008), no mercado das empresas comerciais, é possível perceber uma mudança muito rápida com as organizações adotando o conceito de triple bottom line (desempenho financeiro, social e ambiental) e entendendo que a adoção de um SGA cria benefícios e economias tangíveis. Ainda segundo esse mesmo autor, as empresas percebem o potencial de aumentar a imagem ambiental do participante, que por sua vez pode levar a aumento de vendas, melhor capacidade de recrutamento de funcionários talentosos e melhor relacionamento com os órgãos reguladores e stakeholders.

Cunha, Spers e Zylberztajn (2011) realizaram um estudo de percepção de aspectos da sustentabilidade por parte de consumidores do varejo supermercadista no estado de São Paulo a partir de uma certificação do setor que garante a origem dos produtos. Por sua vez, dos Santos Marzall, Gonçalves e Godoy (2016) estudaram a percepção da sustentabilidade no varejo captando a ótica dos colaboradores quanto às práticas de sustentabilidade aplicadas pela empresa no sul do país. Em ambos os casos, revela-se a preocupação em se mensurar os aspectos da sustentabilidade de acordo com a percepção dos stakeholders, enfatizando a relevância da agenda de sustentabilidade para o segmento.

\section{DESENVOLVIMENTO CONCEITUAL}

De modo a identificar as práticas de sustentabilidade que vêm sendo adotadas nas principais redes de supermercado no mundo e no Brasil, utilizou-se como referência pesquisa elaborada por Seiffert (2007). Das doze categorias definidas pela autora, destacou as mais consensuais entre as pesquisadas a partir de diversos pesquisadores, denominando-as, por sua vez, como "Soluções prioritárias", a saber: reduzir o crescimento populacional; diminuir a pobreza e desigualdades; praticar a agricultura sustentável; proteger as florestas e outros habitats; utilizar a energia de modo sustentável; utilizar a água de modo sustentável e reduzir a geração de lixo (Seiffert, 2007).

Com relação à adoção de SGAs, de acordo com Barbieri (2007), “[...] a política ambiental é uma declaração da organização expondo suas intenções e princípios gerais a seu desempenho 
ambiental global, que provê uma estrutura para ação e definição de seus objetivos e metas ambientais", devendo ser apropriada "[...] à natureza, escala e impactos ambientais das atividades, produtos e serviços da organização".

Assim, a adoção da sustentabilidade por parte das empresas supermercadistas se daria a partir (1) das prioridades internacionais sobre sustentabilidade; e (2) da política ambiental, um dos pilares para a implantação do SGA em uma empresa.

Adotou-se a premissa de que existe uma defasagem entre o estágio atual das práticas voltadas à sustentabilidade nos supermercados que atuam no Brasil e os que são reconhecidos como mais avançados nesse aspecto e que atuam no exterior e se buscou identificar as práticas voltadas à sustentabilidade no conjunto de supermercados investigados.

\section{MÉTODO}

O estudo é de natureza exploratória e qualitativa e baseou-se em dados secundários obtidos nos sítios oficiais das empresas objeto da pesquisa. É importante ressaltar que pelo fato de terem sido utilizadas informações oficiais, as conclusões são também referentes às práticas de sustentabilidade conforme relatado, ou divulgado, pelas empresas. Foram consultados documentos nos sítios das empresas, no período de agosto de 2010 a novembro de 2011, como relatórios anuais de sustentabilidade e dados sobre os SGAs, dentre outros que contivessem dados acerca das práticas de sustentabilidade e meio ambiente nos supermercados em análise (Carrefour, 2009; Carrefour, 2010; Carrefour 2011a; 2011b; 2011c; 2011d; Carrefour, 2012; Coop Ambiente, 2012; Coop Italia, 2007; 2011; E-Coop, 2012; Grupo Pão de Açúcar, 2011; 2012a; 2012b, Tesco, 2010, 2012; Tesco PLC, 2011; Walmart Brasil, 2008, 2010, 2011; Walmart Corporativo, 2011; Walmart Internacional, 2011; Walmart Sustentabilidade, 2011; Whole Foods Market, 2011a, 2011b).

Para o desenvolvimento dessa pesquisa, adotou-se como objeto de estudo o formato do varejo supermercadista. Os procedimentos para consecução da pesquisa compreenderam as seguintes atividades:

a) Seleção da amostra: escolha das redes internacionais e nacionais reconhecidas em boas práticas de RSE e com SGA implantado ou que adotem práticas de gestão ambiental, de modo a que possuam política ambiental estabelecida;

b) Estudo documental: coleta de informações sobre a política ambiental e as práticas de gestão ambiental das empresas selecionadas por meio de dados secundários obtidos por fontes oficiais das próprias empresas;

c) Interpretação e análise dos dados: análise do conteúdo da política ambiental de cada rede de varejo supermercadista escolhida nesta pesquisa com relação às prioridades internacionais e as soluções prioritárias para sustentabilidade sintetizadas por Seiffert (2007).

A pesquisa exploratória foi realizada com vistas a identificar e selecionar amostra representativa de empresas supermercadistas no mundo e no Brasil, reconhecidamente destacadas em RSE e com política ambiental definida, conforme ressaltada a importância dessa 
integração por Hamza e Dalmarco (2013). Assim, a amostra utilizada é não probabilística, tendo sido montada pelos pesquisadores segundo critério de conveniência do estudo.

O primeiro caso selecionado foi a rede varejista americana Whole Foods Market (WFM), tendo em vista sua menção por Michael Porter, em entrevista a Herzog em 2008, como exemplo de empresa que contempla em sua estratégia as perspectivas financeira e social. O segundo caso escolhido provém do relatório elaborado pela organização Consumers International (Cl), que em seu sítio oficial (Consumers International, 2010a) se apresenta como uma federação mundial das organizações dos consumidores e representa mais de 220 grupos de consumidores em 115 países. Nesse relatório (Consumers International, 2010b) foi avaliado e efetuado um ranking do envolvimento das empresas europeias com a RSE, no qual a empresa Coop Italia ficou em primeiro lugar. Entre os supermercadistas do exterior foi incluída a rede Tesco, do Reino Unido, devido à sua destacada atuação em RSE e também por ser uma rede com penetração e distribuição mundial.

Para a seleção das representantes brasileiras, fez-se consulta formal ao Instituto Ethos de empresas e responsabilidade social, tendo sido indicadas as empresas Walmart, Grupo Pão de Açúcar (GPA) e Carrefour, destacadas como "exemplos de supermercados que atuam de forma socialmente responsável e que têm diversas ações em relação ao tema." (Informação obtida por meio de consulta via e-mail, com Sr. Victor Barros, da Comunicação e Mobilização do Instituto Ethos). Essas empresas foram também incluídas na pesquisa pela sua representatividade no varejo alimentar brasileiro, uma vez que são as três maiores em faturamento.

A Figura 1 apresenta dados gerais das empresas selecionadas para o desenvolvimento da pesquisa.

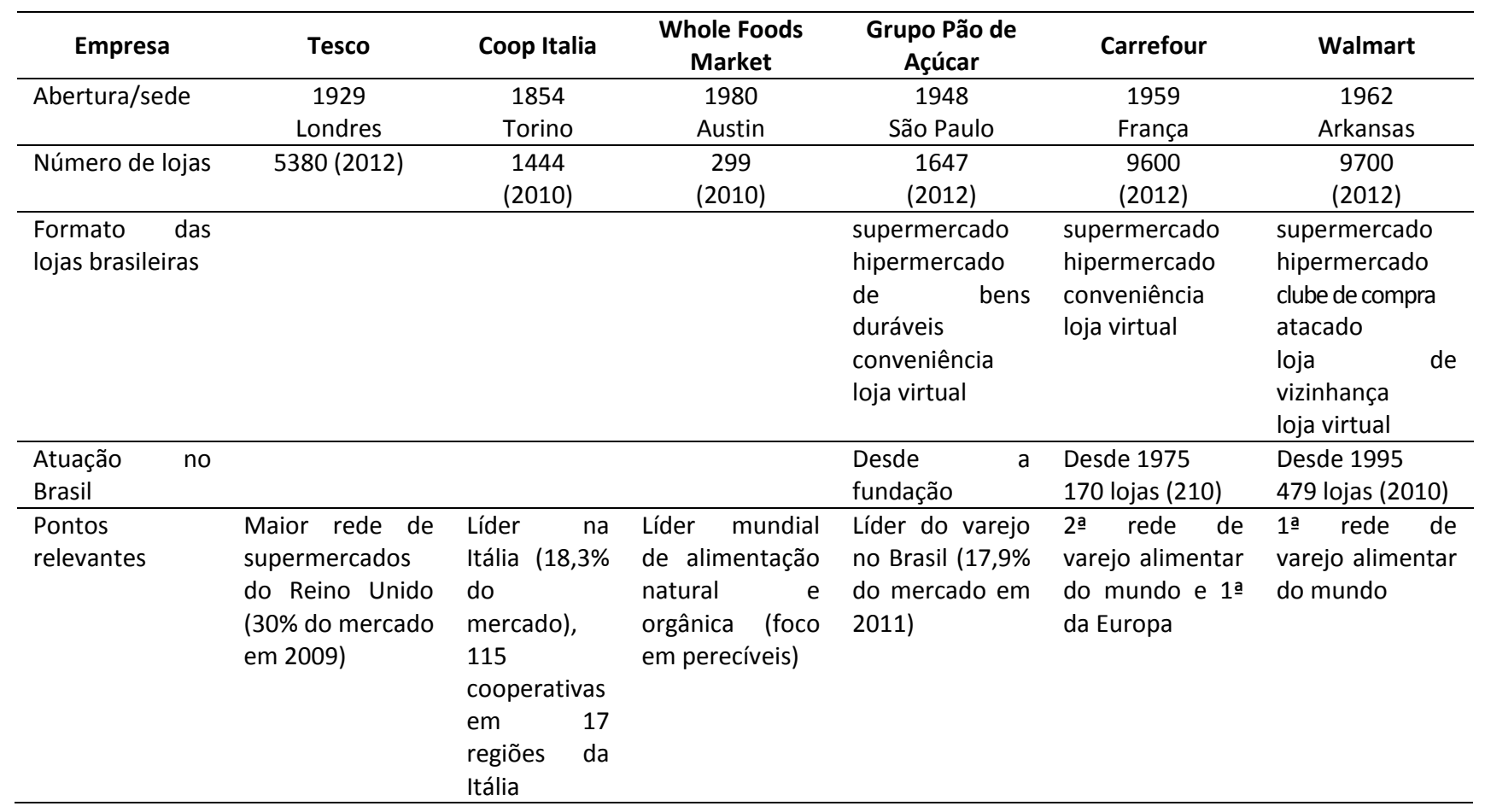

Figura 1: Dados das empresas participantes da pesquisa 
Há que destacar algumas limitações da pesquisa. Foi realizada uma interpretação livre da política ambiental das empresas com relação a uma síntese das prioridades internacionais de sustentabilidade, por isso a abordagem qualitativa. As práticas ambientais tendem a promover a sustentabilidade, mas são apenas um elemento nessa relação. A pesquisa desenvolveu-se a partir de dados secundários sobre a declaração de conduta ambiental das empresas que é divulgada pelas mesmas. Cabe ainda ressalvar que embora duas das unidades consideradas como nacionais sejam origem internacional, foram analisados dados apenas das filiais no Brasil, não sendo escopo desta pesquisa verificar eventual influência da matriz nas unidades nacionais.

\section{RESULTADOS}

Apresentam-se os resultados da análise da política ambiental das empresas selecionadas na pesquisa e a inserção dos elementos dessas políticas nas prioridades internacionais para a sustentabilidade identificadas por Seiffert (2007).

\subsection{Análise das políticas de sustentabilidade}

A análise das políticas de sustentabilidade foi realizada a partir dos dados declarados pelas empresas selecionadas para pesquisa nos seus sítios oficiais. As empresas que possuem SGA formalizado detalham sua política ambiental. Das três empresas pesquisadas que não têm filial no Brasil, a Coop Itália possui SGA focalizado no controle dos impactos ambientais diretamente relacionados com sua operação; a Tesco tem foco na pegada de carbono e o WFM tem uma política ambiental compromissada e difundida entre seus stakeholders. Comparado o SGA das três empresas nacionais com as internacionais, depreende-se um estágio de implantação do SGA mais incipiente no país. O Walmart brasileiro está avançando rapidamente na construção de suas práticas de gestão; o Carrefour tem realizado ações em prol da implementação, embora haja diferenças entre as unidades da Europa com relação à brasileira; e o GPA está desenvolvendo várias ações, mas carece de uma política melhor definida e comunicada.

A Figura 2 sintetiza os principais aspectos da política ambiental das empresas selecionadas para a pesquisa. Os aspectos foram classificados conforme critérios estabelecidos pelos pesquisadores a partir da comparação dos resultados da amostra.

\begin{tabular}{|c|c|c|c|c|c|c|}
\hline $\begin{array}{c}\text { Aspectos } \\
\text { principais da } \\
\text { política ambiental }\end{array}$ & Tesco & Coop Italia & $\begin{array}{c}\text { Whole Foods } \\
\text { Market }\end{array}$ & $\begin{array}{c}\text { Grupo Pão de } \\
\text { Açúcar }\end{array}$ & Carrefour & Walmart \\
\hline $\begin{array}{l}\text { Foco ambiental } \\
\text { produtos que } \\
\text { comercializa }\end{array}$ & intermediário & alto & alto & baixo & baixo & intermediário \\
\hline $\begin{array}{ll}\text { Redução } & \text { do } \\
\text { consumo } & \text { de } \\
\text { energia } & \\
\end{array}$ & Sim & Sim & Sim & Sim & Sim & Sim \\
\hline $\begin{array}{l}\text { Conservação de } \\
\text { recursos naturais }\end{array}$ & Sim & Sim & Sim & Sim & Sim & Sim \\
\hline Gestão resíduos & Sim & Sim & Sim & Sim & Sim & Sim \\
\hline $\begin{array}{l}\text { Foco em causa que } \\
\text { extrapola a área de } \\
\text { atuação }\end{array}$ & $\begin{array}{l}\text { Mudanças } \\
\text { climáticas } \\
\text { (pegada de } \\
\text { carbono) }\end{array}$ & $\begin{array}{l}\text { Mudanças } \\
\text { climáticas } \\
\text { consumo } \\
\text { sustentável }\end{array}$ & $\begin{array}{l}\text { Clima global e } \\
\text { proteção das } \\
\text { florestas, ar e } \\
\text { rios não }\end{array}$ & $\begin{array}{l}\text { Desenvolvi- } \\
\text { mento } \\
\text { socioambiental } \\
\text { dar região }\end{array}$ & $\begin{array}{l}\text { Proteção de } \\
\text { biodiversidade, } \\
\text { proteção de } \\
\text { recursos }\end{array}$ & $\begin{array}{l}\text { Redução } \\
\text { recursos } \\
\text { naturais, } \\
\text { redução }\end{array}$ \\
\hline
\end{tabular}




\begin{tabular}{|c|c|c|c|c|c|c|}
\hline & & & $\begin{array}{l}\text { contaminados, } \\
\text { segurança } \\
\text { alimentar, } \\
\text { cultivo de } \\
\text { alimentos } \\
\text { orgânicos }\end{array}$ & amazônica & $\begin{array}{l}\text { naturais, } \\
\text { mudanças } \\
\text { climáticas }\end{array}$ & $\begin{array}{l}\text { gases nocivos à } \\
\text { camada de } \\
\text { ozônio }\end{array}$ \\
\hline $\begin{array}{l}\text { Foco em causa } \\
\text { relacionada ou não } \\
\text { ao negócio }\end{array}$ & Não observada & $\begin{array}{l}\text { Bem estar de } \\
\text { animais, } \\
\text { desenvolvi- } \\
\text { mento de } \\
\text { culturas } \\
\text { orgânicas, } \\
\text { pesca } \\
\text { sustentável, } \\
\text { proteção dos } \\
\text { golfinhos e do } \\
\text { atum, } \\
\text { impactos da } \\
\text { produção do } \\
\text { óleo de palma }\end{array}$ & $\begin{array}{l}\text { Impactos da } \\
\text { produção do } \\
\text { óleo de palma }\end{array}$ & Não observada & Não observada & $\begin{array}{ll}\text { Compra } & \\
\text { responsável } & \text { na } \\
\text { cadeia } & \text { de } \\
\text { pescado } & \end{array}$ \\
\hline $\begin{array}{l}\text { Compartilhamento } \\
\text { de valores }\end{array}$ & Alto & Alto & Alto & Baixo & Baixo & Intermediário \\
\hline $\begin{array}{l}\text { Envolvimento } \\
\text { stakeholders }\end{array}$ & Alto & Alto & Alto & Baixo & Baixo & Alto \\
\hline
\end{tabular}

Figura 2: Pontos identificados da política ambiental das empresas selecionadas

Com relação ao foco ambiental nos produtos comercializados: como o setor de varejo supermercadista revende produtos de diversos fornecedores, seus princípios em relação aos cuidados do meio ambiente podem entrar em conflito com os impactos ambientais de alguns produtos comercializados, como por exemplo, produtos químicos de limpeza que possam contaminar o solo. Observa-se, quanto a este ponto, que o WFM não comercializa produtos com determinados ingredientes. O Walmart e a Coop Itália envolvem fornecedores para desenvolvimento de produtos que já estão no mercado, de modo a melhorar seu desempenho ambiental. O GPA e Carrefour tem atuação focada em produtos de marca própria, com linha particular de produtos desenvolvida de modo ambientalmente adequado.

Quanto à redução do consumo de energia: todas as empresas pesquisadas incorporam a redução de energia em sua política. Além de estar alinhada com princípios ambientais, a atuação nesta área reverte em ganhos financeiros imediatos importantes em um setor competitivo como o varejo supermercadista.

Quanto à conservação de recursos naturais: aspecto unânime na amostra da pesquisa, todas as empresas reconhecem que os recursos naturais são escassos e é muito importante sua conservação, que faz parte inclusive da própria definição de sustentabilidade.

Quanto à gestão de resíduos próprios e dos stakeholders: as empresas, sem exceção, possuem gestão de resíduos, materializada pela política dos 3 Rs (reduzir, reutilizar, reciclar). Essa preocupação se revelou mais ampla do que apenas considerar os resíduos provocados pela própria operação. Os supermercados estão criando estações de reciclagem para consumidores dispensarem lâmpadas, baterias, dentre outros para reciclagem e destinação final adequada. Muitos desses produtos são provenientes da própria rede. 
Quanto ao foco em causa que extrapola a sua área de atuação: da análise das políticas ambientais da amostra de empresas selecionadas para a pesquisa, depreendeu-se que, sem exceção, todos os supermercados "abraçam uma grande causa" revestida de benefícios para a humanidade em geral, que extrapola o alcance da sua própria operação. A maioria das empresas selecionadas, à exceção do Grupo Pão de Açúcar, divulga mais de uma grande causa. As grandes causas referem-se principalmente a temas relativos a mudanças climáticas, manutenção dos recursos naturais, biodiversidade, consumo sustentável e segurança alimentar.

Quanto ao foco em causa relacionada ou não ao negócio: metade das redes de supermercado pesquisadas (WFM e Coop Italia no exterior e Walmart, no Brasil) também adota em sua política alguma causa, que pode ou não estar relacionada ao negócio, com menor amplitude de alcance para a sociedade como um todo. Essas causam referem-se, principalmente, aos impactos na produção de palma, cadeia do pescado e produtos orgânicos. Aparentemente a definição dessa causa pode estar relacionada à importância dada para a empresa ou para seus sócios à mesma.

Quanto ao compartilhamento de valores: os líderes do setor supermercadista afirmam estarem investindo no meio ambiente, buscando tornar seus negócios mais sustentáveis. O Whole Foods Market é uma das empresas que mais crescem, com maior lucratividade, no mercado norte americano, tendo desde o início das suas operações atuação relacionada à saúde e ao meio ambiente. A Coop Itália é líder no varejo supermercadista italiano. A Tesco, além de líder do setor no Reino Unido, é um exemplo de que a incorporação de valores ambientais, ainda que recente, pela definição de uma política ambiental e sua disseminação em sua cultura empresarial traz bons resultados rapidamente. Com relação às nacionais, percebe-se que esse compartilhamento de valores não é tão disseminado. O Walmart vem procedendo esta mudança em velocidade compatível com seu porte empresarial. A agilidade de incorporação de novos valores na cultura pode ser reduzida em função do número de funcionários que a empresa possui. Observa-se que o Carrefour, como segundo maior supermercadista mundial, no Brasil percebe o valor deste modelo de atuação, incorporando a gestão social e ambiental e, também está aos poucos ampliando sua organização neste sentido. O Grupo Pão de Açúcar, que é o maior varejista brasileiro, mesmo não possuindo um sistema de gestão ambiental formalizado, possui diversas ações ambientais em curso (lojas verdes, estações de reciclagem, programa caixa verde, programa descarte correto de medicamentos, sacolas retornáveis, gestão de resíduos, uso consciente de água e energia dentre outros) e investe nesta atuação.

Quanto ao envolvimento dos stakeholders: o envolvimento de funcionários, consumidores, fornecedores e todos que possuam relacionamento com a empresa é importante para que a cultura ambiental seja rapidamente disseminada na empresa. Incluir esse envolvimento na política ambiental deve criar comprometimento e consolidar a própria política. Pela amostra pesquisada, observa-se que as empresas que possuem maior inclusão dos stakeholders são as que estão mais consolidadas ambientalmente: Whole Foods Market, Coop Itália e Tesco. No país, o Walmart mostra-se mais avançado que as outras duas principais cadeias de supermercados. 


\subsection{Prioridades internacionais para sustentabilidade}

Os elementos presentes na política ambiental das empresas selecionadas (Figura 2) em análise cruzada às principais prioridades internacionais para sustentabilidade sintetizadas por Seiffert (2007) permitiu a elaboração da Figura 3. Nesta mesma figura estão apontadas (em sombreado) também as soluções prioritárias consideradas pela autora.

\begin{tabular}{|c|c|c|c|c|c|c|}
\hline Prioridades/Soluções Prioritárias & Tesco & $\begin{array}{l}\text { Coop } \\
\text { Italia }\end{array}$ & WFM & GPA & Carrefour & Walmart \\
\hline reduzir o crescimento populacional & - & - & - & - & - & - \\
\hline $\begin{array}{l}\text { diminuir a pobreza, as desigualdades } \\
\text { e a dívida do Terceiro Mundo }\end{array}$ & - & - & - & - & - & - \\
\hline praticar a agricultura sustentável & - & - & Sim & - & - & - \\
\hline $\begin{array}{l}\text { proteger florestas e habitats, limitar } \\
\text { a perda de espécies }\end{array}$ & - & - & Sim & Sim & - & - \\
\hline $\begin{array}{l}\text { proteger os recursos oceânicos e } \\
\text { costeiros }\end{array}$ & - & - & - & - & - & Sim \\
\hline $\begin{array}{l}\text { proteger a qualidade da água doce, } \\
\text { melhorar a eficiência do uso da água }\end{array}$ & - & - & Sim & - & - & - \\
\hline aumentar a eficiência energética & - & - & - & - & - & - \\
\hline $\begin{array}{l}\text { desenvolver fontes renováveis de } \\
\text { energia }\end{array}$ & - & - & Sim & - & - & - \\
\hline $\begin{array}{l}\text { limitar os gases de estufa e outros } \\
\text { poluentes atmosféricos }\end{array}$ & Sim & Sim & - & & Sim & Sim \\
\hline proteger a camada de ozônio & Sim & & Sim & & & Sim \\
\hline $\begin{array}{l}\text { reduzir a geração de lixo, reciclar os } \\
\text { rejeitos (resíduos e efluentes) }\end{array}$ & Sim & Sim & Sim & Sim & Sim & Sim \\
\hline $\begin{array}{l}\text { transferir os gastos militares ao } \\
\text { desenvolvimento sustentável }\end{array}$ & - & - & - & - & - & - \\
\hline
\end{tabular}

Figura 3: Prioridades internacionais de sustentabilidade e soluções prioritárias correlacionadas com os aspectos principais da política ambiental das empresas pesquisadas.

Fonte: produzida pelos autores a partir de Seiffert (2007).

Há que se destacar como ressalva dessa análise que a interpretação dos aspectos da política ambiental das empresas selecionadas foi realizada a partir do exposto em seus veículos oficiais de divulgação (sítios na Internet) com relação às prioridades internacionais de sustentabilidade. $\mathrm{Na}$ análise, buscou-se associar o conteúdo da política ambiental ao conteúdo das prioridades internacionais de sustentabilidade.

Foram identificados alguns resultados acerca da associação das prioridades internacionais de sustentabilidade à política ambiental das grandes redes supermercadistas investigada.

A rede Whole Foods Market é a que considera em sua política maior número de prioridades de sustentabilidade, das seis observadas, quatro coincidem com as soluções prioritárias. As redes Coop Italia, Grupo Pão de Açúcar e Carrefour são as que consideram em sua política menor número de prioridades de sustentabilidade, com duas prioridades cada um, dessas apenas uma, do Grupo Pão de Açúcar, corresponde também a solução prioritária. Os Grupos WalMart e Tesco posicionam-se em situação intermediária entre esses extremos, ambos com apenas uma solução prioritária. Não se verifica um padrão nítido de superioridade quanto à preocupação com inserção de prioridades de sustentabilidade na política ambiental, salvo pelo posicionamento da Tesco, entre as empresas internacionais avaliadas e as observadas por meio de dados nacionais. Os aspectos de sustentabilidade diretamente relacionados com os negócios das 
empresas com redução de lixo e reciclagem aparecem em todas as políticas analisadas. As prioridades relacionadas a controle de emissões de gases de efeito estufa e proteção da camada de ozônio são as prioridades de sustentabilidade com maior frequência de ocorrência nas políticas ambientais pesquisadas. À exceção das prioridades mencionadas como não verificadas, as referentes à prática de agricultura sustentável, proteção dos recursos pesqueiros, qualidade de água doce e fontes renováveis de energia aparecem com apenas uma associação.

A Tabela 1 apresenta a comparação da quantidade de soluções prioritárias associadas aos aspectos principais da política ambiental das empresas pesquisadas no Brasil e no exterior.

Tabela 1:

Quantidade de soluções prioritárias relativas à sustentabilidade no Brasil e no exterior.

\begin{tabular}{lcc}
\hline Soluções prioritárias & Brasil & Exterior \\
\hline Reduzir o crescimento populacional & 0 & 0 \\
\hline $\begin{array}{l}\text { Diminuir a pobreza, as desigualdades e a dívida do Terceiro } \\
\text { Mundo }\end{array}$ & 0 & 0 \\
\hline praticar a agricultura sustentável & 0 & 1 \\
\hline proteger florestas e habitats, limitar a perda de espécies & 1 & 1 \\
\hline aumentar a eficiência energética & 0 & 0 \\
\hline desenvolver fontes renováveis de energia & 0 & 1 \\
\hline $\begin{array}{l}\text { reduzir a geração de lixo, reciclar os rejeitos (resíduos e } \\
\text { efluentes) }\end{array}$ & 3 & 3 \\
\hline Total & $\mathbf{4}$ & $\mathbf{6}$ \\
\hline
\end{tabular}

Fonte: Os autores.

Da análise das prioridades de sustentabilidade sintetizadas por Seiffert (2007), descritas na Tabela 1, pode-se considerar que: algumas categorias são muito abrangentes ou especificas como "reduzir o crescimento populacional" e "transferir os gastos militares ao desenvolvimento sustentável" e dificilmente estariam incluídas na política de um supermercado; outras categorias não figuram na política dos supermercados investigados, mas poderiam estar presentes como "diminuir a pobreza, as desigualdades e a dívida do Terceiro Mundo" e "aumentar a eficiência energética"; apenas Tesco considerou as prioridades como agricultura sustentável e promoção da qualidade da água doce, que são práticas com relação indireta ao setor supermercadista; a Whole Foods Market possui uma política ambiental mais aderente às metas de promoção de sustentabilidade, isso talvez se deve ao fato que essa foi uma das premissas do negócio desde seu início; a Coop Italia, mesmo sendo referência em RSE, possui baixa inserção de aspectos prioritários de sustentabilidade. Talvez dado foco forte no controle dos impactos ambientais diretamente relacionados com sua operação, que embora relevantes, nem sempre estão explícitos nas prioridades internacionais de sustentabilidade; o Grupo Pão de Açúcar e o Carrefour tem baixa inserção de aspectos de sustentabilidade em sua política. Essa constatação pode se subsidiar na premissa de que são as redes em que estão em processo de construção e implementação de SGA no país; a Walmart vem avançando rapidamente na construção de suas práticas de gestão nos últimos tempos e isso se reflete em suas práticas de sustentabilidade.

\section{DISCUSSÃO}

Da análise das prioridades de sustentabilidade sintetizadas por Seiffert (2007) observa-se que há categorias muito abrangentes, nas quais os supermercados evidentemente não poderiam 
exercer a menor influência, como "reduzir o crescimento populacional" e "transferir os gastos militares ao desenvolvimento sustentável". Outras categorias de prioridades, também enquadradas nas soluções prioritárias, embora bastante amplas, poderiam merecer destaque na política ambiental de supermercados. Dada à capilaridade de distribuição desse setor e também ao relacionamento direto com o consumidor final, uma atuação nesse sentido poderia ser também considerada uma grande causa, que poderia levar à formação de opinião e reflexão acerca de temas que são pauta mundial em desenvolvimento sustentável. Tais temas, que não foram observados em nenhuma política ambiental verificada, seriam: "diminuir a pobreza, as desigualdades e a dívida do Terceiro Mundo" e "aumentar a eficiência energética". Por outro lado o tema resíduos está presente em todas as empresas investigadas e isso se alinha ao identificado por de Araujo e Carvalho (2011), inclusive que a inserção da redução de resíduos apresenta-se como estratégia ambiental que se configura em uma oportunidade para obter vantagem competitiva de redução de custos.

Outra solução, que aparece apenas na política ambiental da Tesco, prática de agricultura sustentável, tem relação direta com as atividades do setor supermercadista, pelo fornecimento de alimentos frescos, e poderia ser explorada pelo segmento para contribuição à promoção de sustentabilidade. Correlação similar poderia ser realizada para a promoção da qualidade de água doce, também só assinalada pela Tesco.

De todas as redes pesquisadas, o Whole Foods Market é a que possui uma política ambiental mais aderente às metas de promoção de sustentabilidade. Talvez a razão para isso resida no fato de ter sido criada recentemente e já com a incorporação da variável ambiental em seu negócio, como enfatizado por Hamza e Dalmarco (2013) como uma tendência de inserção da sustentabilidade na estratégia da empresa.

O fato da Coop Italia, ser reconhecida internacionalmente como referência em RSE e ter sua política com baixa inserção de aspectos de sustentabilidade, merece alguns comentários. Uma análise mais atenta do conteúdo da sua política ambiental permite constatar que embora a empresa destaque princípios de desenvolvimento sustentável em seus negócios, observa-se um foco forte no controle dos impactos ambientais diretamente relacionados com sua operação, que embora relevantes, nem sempre estão explícitos nas prioridades internacionais de sustentabilidade.

A Tesco tem sua política ambiental, e consequentemente, de sustentabilidade totalmente apoiada na pegada de carbono e mudanças climáticas, sendo essa a bandeira pela qual é reconhecida.

Com relação às avaliadas pelas unidades nacionais, Grupo Pão de Açúcar e Carrefour, que também tem baixa inserção de aspectos de sustentabilidade em sua política, são as que estão em processo de construção e implementação de SGA no país, talvez sendo essa a justificativa para esse achado. Muito embora, as prioridades internalizadas na política do GPA sejam as consideradas como soluções prioritárias.

Com relação ao Walmart, analisado por meio das unidades de varejo no país, o estabelecimento da sua política ambiental em três grandes eixos, clima e energia, resíduos e 
produtos, e como isso está impresso em sua política, faz com que a empresa, nessa análise, apareça como uma dos setores em que as prioridades de sustentabilidade estão mais expressas em sua política. Tal fato possa ser corroborado pela impressão que essa rede vem avançando rapidamente na construção de suas práticas de gestão nos últimos tempos. Esse achado se coaduna aos observados por Hamza e Dalmarco (2013) cuja pesquisa também apontou que dentre as redes nacionais o Walmart é a que consegue efetivamente ajustar as práticas de gestão ambiental e sustentabilidade em sua estratégia de negócios.

De um modo geral tanto nacional quanto internacional as prioridades da sustentabilidade emergem de modo tímido como destacado por Delai e Takahashi (2013) e Wiese et al. (2012).

\section{CONCLUSÕES}

Excluídas as prioridades internacionais de sustentabilidade que extrapolam a área de influência e de decisão das redes de varejo supermercadista no mundo, pode-se considerar, de modo geral, que, em maior ou menor grau, os principais supermercados estão atentos à promoção de sustentabilidade na agenda ambiental do seu negócio. Resta também considerar se a ampliação da inserção das prioridades de sustentabilidade, ao menos das principais soluções prioritárias, poderia reverter em ganhos líquidos e benefícios tácitos para as operações dos negócios. Talvez explorar esse aspecto possa contribuir para ampliar a inserção da variável ambiental e de sustentabilidade nos negócios supermercadistas, revertendo em melhorias nas próprias condições do ambiente e quem sabe gerando ainda lucros.

Uma comparação entre o desempenho geral da inclusão do tema sustentabilidade, por meio da consideração de soluções prioritárias em sua política, entre as empresas supermercadistas internacionais e as brasileiras sugere um maior avanço das primeiras. Das sete soluções prioritárias, três não aparecem em nenhuma rede investigada, duas pertencem às preocupações com a temática de sustentabilidade tanto das redes do exterior quanto as locais e as últimas duas ainda figuram apenas como temas a considerar pelas empresas estrangeiras. Por fim, das soluções prioritárias, nenhuma foi exclusivamente considerada por uma rede supermercadista brasileira. Essas considerações, embora sem o uso de técnicas estatísticas, confirmam a premissa de que há uma defasagem entre o estágio atual das práticas voltadas à sustentabilidade nos supermercados que atuam no Brasil e aqueles que são reconhecidos como mais avançados nesse aspecto e que atuam no exterior.

Há que se destacar que a análise aqui realizada é uma interpretação livre da política ambiental das empresas com relação a uma síntese das principais prioridades internacionais de sustentabilidade. Seguramente alguns aspectos, inclusive de relevância, podem não ter sido incluídos nessa análise prejudicando os resultados finais encontrados. Por isso, optou-se por não realizar um tratamento estatístico quantitativo, a abordagem é qualitativa para que se exponham alguns elementos básicos e preliminares sobre o alinhamento das práticas ambientais praticadas pelo setor varejista supermercadista com relação à promoção de sustentabilidade.

Outro ponto a considerar refere-se que as práticas ambientais tendem a promover a sustentabilidade, mas são apenas um elemento nessa relação. Portanto, estudos mais dirigidos e 
amplos deveriam ser realizados no sentido de corroborar as afirmativas tecidas nesta pesquisa. Outro ponto a considerar é eventuais vieses de análise, visto que a pesquisa desenvolveu-se a partir de dados secundários sobre a declaração de conduta ambiental das empresas divulgadas pelas próprias.

Enfim, espera-se que esta pesquisa possa estimular desenvolvimento de novas experiências na investigação das práticas ambientais e de sustentabilidade no varejo, dada a importância que esse segmento exerce nas atividades econômicas mundiais e no cotidiano da sociedade.

O estudo contribui ao reunir evidência empíricas da forma de atuação em relação ao meio ambiente de redes de supermercados que possuem destaque em seu setor e que, ao menos indiretamente, servem como baliza às demais empresas. Também é uma contribuição que merece ser mencionada o método empregado na análise que consistiu na confrontação das práticas dos supermercados com as prioridades de Seiffert. Finalmente, também é preciso mencionar que ao reunir dados dessas grandes redes empresas, está sendo apresentado a forma como um percentual muito expressivo do faturamento dos supermercados encara sua responsabilidade social.

\section{AGRADECIMENTO}

Os autores agradecem à biblioteconomista Edna Gubitoso do IPT pela revisão das citações e referências de acordo com as normas APA.

\section{REFERÊNCIAS}

Amadeu Jr, A., Gelman, J. J., \& Macedo, L. C. (2008). A mobilização do setor varejista para a responsabilidade social: do assistencialismo ao alinhamento estratégico. In: J. J Gelman \& J. Parente (Orgs.). Varejo socialmente responsável. (Cap. 1, pp. 15-32). Porto Alegre: Bookman.

Aragón-Correa, J. A. (1998). Strategic proactivity and firm approach to the natural environment. Academy of Management Journal, 41(5), 556.

Araujo, G. J. F., \& Carvalho, C. M. (2011). As políticas sustentáveis aplicadas às redes varejistas. Revista Administração em Diálogo-RAD, 13(1), 47-63.

Associação Brasileira de Normas Técnicas. (2012). NBR ISO 16:001: 2012 - Responsabilidade Social - Sistema de gestão - Requisitos. Rio de Janeiro: ABNT.

Associação Brasileira de Supermercados. (2008a). Abras divulga ranking de supermercados. São Paulo: APAS. Recuperado em 16 abril, 2013, de http://www.portalapas.org.br/default.asp?resolucao=1680X1050

Associação Brasileira de Supermercados. (2008b). Guia prático APAS: supermercado sustentável. São Paulo: APAS.

Associação Brasileira de Supermercados. (2011). Guia da loja verde. São Paulo: APAS.

Barbieri, J. C. (2004). Gestão ambiental empresarial: conceitos, modelos e instrumentos. São Paulo: Saraiva.

Barros, R. (2005). Instrumentos de gestão ambiental empresarial. Rio de janeiro: FGV ONLINE. 
Borger, F. G. (2006). Responsabilidade social corporativa: a dimensão ética, social e ambiental na gestão das organizações. In: A. Vilela Jr, \& J. Demajorovic. (Orgs.). Modelos e ferramentas de gestão ambiental: desafio e perspectivas para as organizações (pp. 13-40). São Paulo: Editora SENAC.

Braga Jr, S. S. (2007). Gestão ambiental no varejo: um estudo das práticas de logística reversa em supermercados de médio porte. Dissertação de Mestrado, Faculdade de Economia, Administração e Contabilidade de Ribeirão Preto, Universidade de São Paulo, Ribeirão Preto, $\mathrm{SP}$, Brasil.

CARREFOUR. (2009). Relatório de desenvolvimento sustentável. Recuperado em 06 agosto, 2010, de http://www.grupocarrefour.com.br/wp-content/uploads/2010/02/27646_RDS_2009.pdf

Carrefour. (2010). Relatório de desenvolvimento sustentável 2009. Recuperado em 06 agosto, 2010, de http://www.grupocarrefour.com.br/wpcontent/uploads/2010/02/27646_RDS_2009.pdf

Carrefour. (2011a). Consulta geral a homepage oficial Brasil. Recuperado em 06 setembro, 2011, de http://www.carrefour.com.br

Carrefour. (2011b). Consulta geral a homepage oficial do grupo no Brasil. Recuperado em 08 setembro, 2011, de http://www.grupocarrefour.com.br/

Carrefour. (2011c). Consulta geral ao site c-laterre.fr. (site do desenvolvimento sustentável do Carrefour). Recuperado em 06 setembro, 2011, de http://www.claterre.fr/?svc_mode=E\&g=233033193305\&svc_campaign=rubrique\&svc_partner=ClaTerre\&sv c_position=CRF\&estat_url=http\%3A\%2F\%2Fwww.c-laterre.fr\%2F

Carrefour. (2011d). Rapport expert 2010: Le développement durable chez Carrefour. Recuperado em 06 setembro, 2011 de, http://www.carrefour.com/docroot/groupe/C4com/Commerce\%20responsable/Publications/R DD_Expert_2010_complet_250711_DEF.pdf

Carrefour. (2012). Consulta geral a homepage oficial mundial. Recuperado em 09 maio, 2012, de http://www.carrefour.com/

Christchurch City Council. (2008). Target sustainability - Supermarket business guide. Christchurch: CCC. Recuperado em 13 abril, 2013, de http://www.targetsustainability.co.nz/SectorGuides/TargetSustainabilitySupermarketBusinessG uide.pdf

Consumers International. (2010a). Consulta geral a homepage oficial. Recuperado em 01 dezembro, 2010, de http://www.consumersinternational.org/

Consumers International. (2010b). Les supermarchés europeéns aux banc d'essai: sont-ils à La hauteur de leurs responsabilités em matière de conditions de travail dans Le monde em développements? Recuperado em 27 novembro, 2010, de <http://www.consumersinternational.org/media/394318/checkedout-fran\%C3\%A7ais-02.pdf

Coop Ambiente. (2012). Consulta geral a homepage. Recuperado em 21 fevereiro, 2012, de http://www.coopambiente.it/

Coop Italia. (2007). L'impegno di Coop per l'ambiente. Recuperado em 14 novembro, 2010, de <http://www.e-coop.it/CoopRepository/COOP/Coopltalia/file/fil00000039351.pdf

Coop Itália. (2011). 2010 Settimo rapporto sociale nazionale: della cooperazione di consumatori. Casalecchio di Reno: Euro Coop Itália. Recuperado em 21 fevereiro 2011, de http://www.ecoop.it/portalWeb/stat/docPortale/doc00000057190/true/rapporto-sociale-nazionale-.dhtml 
Cruz, L. B., Pedrozo, E., \& Martinet, A. (2007). Estratégias de desenvolvimento sustentável em grupos multinacionais: o estudo de dois casos franceses no setor do varejo. Revista de Gestão Social e Ambiental, 1(3), 58-78.

Cunha, C. F., Spers, E. E., \& Zylbersztajn, D. (2011). Percepção sobre atributos de sustentabilidade em um varejo supermercadista. RAE-Revista de Administração de Empresas, 51(6), 542-552.

Delai, I., \& Takahashi, S. (2013). Corporate sustainability in emerging markets: insights from the practices reported by the Brazilian retailers. Journal of Cleaner Production, 47(5), 211-221.

Demajorovic, J. (2006). Ecoeficiência em serviços: diminuindo impactos e aprimorando benefícios ambientais. In: A. Vilela Jr \& J. Demajorovic, (Org.). Modelos e ferramentas de gestão ambiental: desafio e perspectivas para as organizações (pp. 169-198).São Paulo: Editora SENAC.

E-coop. (2012). Consulta geral a homepage oficial. Recuperado em 21 fevereiro, 2012, de http://www.e-coop.it/portalWeb/portale/index.jsp

Epelbaum, M. (2006). Sistemas de gestão ambiental. In: A. Vilela Júnior \& J. Demajorovic (Orgs.) Modelos e ferramentas de gestão ambiental: desafio e perspectivas para as organizações. (pp. 115-148). São Paulo: Editora SENAC.

Erol, I., Cakar, N., Erel, D., \& Sari, R. (2009). Sustainability in the Turkish Retailing Industry. Sustainable Development, 17(1), 49-67.

Food Market Institute. (2013). Sustainability guide - implementing susytainability in operation. Arlington: FMI. Recuperado em 12 abril, 2013, de http://www.fmi.org/docs/sustainability/sustainability_quick_start_guide_marketing.doc?sfvrsn $=2$

Fundação Getulio Vargas. (2005). Indicadores de responsabilidade social nas empresas varejistas. São Paulo: FGV.

Grupo Pão de Açúcar (2011). Relatório anual e de Sustentabilidade 2010. São Paulo: GPA. $\begin{array}{lllll}\text { Recuperado em } 20 & \text { fevereiro de }\end{array}$ http://www.gpari.com.br/grupopaodeacucar/web/conteudo_pt.asp?idioma=0\&conta=28\&tipo $=29910$

Grupo Pão de Açúcar. (2012a). Consulta geral a homepage relação com investidores. Recuperado $\begin{array}{llll}\text { em } & 20 & \text { fevereiro } & 2012,\end{array}$ http://www.gpari.com.br/grupopaodeacucar/web/default_pt.asp?idioma=0\&conta=28

Grupo Pão de Açúcar. (2012b). Consulta geral a homepage oficial. Recuperado em 20 fevereiro 2012, de http://www.grupopaodeacucar.com.br/home.htm

Hamza, K. M., \& Dalmarco, D. D. A. S. (2013). Integração entre estratégia competitiva e práticas de responsabilidade social corporativa: um estudo exploratório nos cinco maiores supermercados brasileiros. Revista de Gestão Social e Ambiental, 6(3), 78-95.

Hart, S. L. (1997). Beyond Greening: Strategies for a sustainable world. Harvard Business Review, 75(1), 66-76.

Instituto Brasileiro de Geografia e Estatística. (2012). Consulta geral a homepage oficial. Recuperado em $10 \quad$ maio, 2012, de http://www.ibge.gov.br/home/estatistica/economia/contasnacionais/2009/tabelas_pdf/tab10. pdf

Instituto Ethos. (2010). Consulta geral a homepage oficial. Recuperado em 27 novembro, 2010, de http://www1.ethos.org.br/EthosWeb/Default.aspx

Moura, L. A. A. (2011). Qualidade e gestão ambiental: sustentabilidade e ISO 14.001. 6. ed. Belo Horizonte: Del Rey Editora. 
Philippi Junior, A., Roméro, M. A., \& Bruna, G. C. (2009). Uma introdução à questão ambiental. In: A. Philippi Junior, M. A. Roméro, \& G. C. Bruna (Eds.) Curso de gestão ambiental (Cap. 1, pp.316). Barueri: Editora Manole.

Porter, M. E., \& Kramer, M. R. (2009). Estratégia e sociedade: o vínculo entre vantagem competitiva e a responsabilidade social das empresas. In: M. E. Porter (Ed.). Competição - on competition: estratégias competitivas essenciais (p. 483-507). Rio de Janeiro: Campus.

Porter, M. E., \& Van Der Linde, C. (1995). Green and competitive: ending the stalemate. Harvard Business Review, 73(5), 120-134.

Santos, L. A., Marzall, L. F., Gonçalves, D. L., \& Godoy, L. P. (2016). Análise das práticas sustentáveis no ramo varejista: uma percepção dos colaboradores com ênfase na educação ambiental. Revista Reunir, 6(1), 37-55.

Seiffert, M. E. B. (2007). Gestão ambiental: instrumentos, esferas de ação e educação ambiental. São Paulo: Atlas.

Spence, L., \& Bourlakis, M. (2009). The evolution from corporate social responsibility to supply chain responsibility: the case of Waitrose. Supply Chain Management: An International Journal, 14,(4), 291-302.

Suamir, I. N., Tassou, S. A., \& Marriot, D. (2012). Integration of CO2 refrigeration and trigeneration systems for energy and GHT emission saving in supermarkets. International Journal of Refrigeration, 35(2), 407-417.

Superhiper (2012). Ranking Abras 2012: a análise do autosserviço. São Paulo: Abras.

Superhiper. (2010). Panorama Superhiper 2011. São Paulo: Abras.

Tesco PLC. (2011). Corporate Responsability Report 2011. Recuperado em 17 março, 2012, de http://www.tescoplc.com/media/60113/tesco_cr_report_2011_final.pdf

Tesco. (2010). Environment sustainability statement: Tesco environment store, Greater Eston. Hampshire: Scott Wilson.

Tesco. (2012). Consulta geral a homepage oficial. Recuperado em 17 março, 2012, de http://www.tesco.com/

Varejo Sustentavel. (2012). Consulta geral a homepage oficial. Recuperado em 12 março, 2012, de http://www.varejosustentavel.com.br/

Walker, D. (2008). Sustainability: environment management, transparency and competitive advantage. Journal of Retail and Leisure Property, v.7, 119-130.

Walmart Brasil. (2008). Relatório de sustentabilidade 2008: exercício 2007. Barueri: Ipsis Gráfica e Editora.

Walmart Brasil. (2010). Consulta geral a homepage oficial. Recuperado em 5 agosto, 2010, de http://www.walmartbrasil.com.br/

Walmart Brasil. (2011). Relatório de sustentabilidade 2011: exercício 2010. Barueri: Editora Contadino.

Walmart Corporativo (2011).. Consulta geral a homepage oficial. Recuperado em 1 outubro, 2011, de http://www.walmartstores.com

Walmart Internacional. (2011). Consulta geral a homepage oficial. Recuperado em 1 outubro, 2011, de http://www.walmart.com

Walmart Sustentabilidade. (2011). Consulta geral a homepage oficial. Recuperado em 1 novembro, 2011, de http://www.walmartsustentabilidade.com.br

Wells, C. (2006). Rotulagem ambiental. In: A. Vilela Jr, \& J. Demajorovic. (Orgs.). Modelos e ferramentas de gestão ambiental: desafio e perspectivas para as organizações (pp. 337-361). São Paulo: Editora SENAC. 
Whole Foods Market (2011a). Consulta geral a homepage oficial. Recuperado em 21 junho, 2011, de http://www.wholefoodsmarket.com/>. Acesso em: 21 jun. 2011a.

Whole Foods Market. (2011b). Annual report 2010. Austin, Texas: WFM. Recuperado em 21 junho, 2011, de <http://www.wholefoodsmarket.com/company/pdfs/ar10.pdf

Wiese, A., Kellner, J., Lietke, B., Toporowsi, W., \& Zielke, S. (2012). Sustainability in retailing - a summative content analysis. International Journal of Retail \& Distribution Management, 40 (4), 318-335.

Winandy, A. J. C., \& Gallardo, A. L. C. F. (2014). Análise das práticas de gestão ambiental divulgadas pelo varejo supermercadista. Revista Gestão Industrial, 10(4), 925-948.

World Comission on Environment and Development. (1987). Our common future. Oxford: Oxford University Press. 